\title{
PENGARUH LATIHAN SISTEM POS TERHADAP KETEPATAN CHEST PASS PADA TIM BOLA BASKET PUTRI SMA NEGERI 2 BATANG HARI
}

\author{
${ }^{1}$ Boy Indrayana \\ ${ }^{2}$ Teja Apri Wardana \\ Correspondence: Fakultas Ilmu Keolahragaan Universitas Jambi, Jambi, \\ Indonesia \\ E-mail: boy_indrayana@unja.ac.id
}

\begin{abstract}
Abstrak
Penelitian ini bertujuan untuk mengetahui pengaruh latihan Sistem Pos terhadap ketepatan Passing Chest Pass pada Tim Bola Basket Putri SMA N 2 Batang Hari. yang dilaksanakan mulai tanggal 31 Maret sampai dengan 31 Mei 2016. Objek yang diamati dalam penelitian ini adalah Tim Bola Basket Putri SMA N 2 Batang Hari dengan populasi 30 siswi dan sampel yang diambil berjumlah 15 siswi dengan teknik sampel total sampling. Penelitian ini dilakukan dengan metode eksperimen dengan rancangan pre test dan pos test design, frekuensi latihan selama 6 minggu sebanyak 18 kali pertemuan, yang dilaksanakan di lapangan Bola Basket SMA N 2 Batang Hari. Untuk mengetahui pengaruh latihan Sistem Pos terhadap ketepatan Passing Chest Pass pada Tim Bola Basket Putri SMA N 2 Batang Hari. digunakan 3 uji yaitu: uji normalitas, uji homogenitas varians dan uji hipotesis. Hasil penelitian menunjukkan bahwa latihan Sistem Pos memberikan pengaruh yang signifikan terhadap ketepatan Passing Chest Pass pada Tim Bola Basket Putri SMA $N 2$ Batang Hari. Dari hasil uji normalitas didapat L hit $<$ L tab yaitu pada pre test sebesar $0,013061<0,220$ dan hasil post test sebesar 0,00724 < 0,220, hasil dari uji homogenitas varians menunjukkan bahwa $F$ hit $<F$ tab yaitu 0,95 $<$ 2,48 sedangkan hasil uji hipotesis menunjukkan bahwa $t$ hit $>t$ tab yaitu 7,61> 1,7613. Dari hasil penelitian dapat disimpulkan bahwa terdapat pengaruh latihan Sistem Pos terhadap ketepatan Passing Chest Pass pada Tim Bola Basket Putri SMA N 2 Batang Hari.
\end{abstract}

\section{Kata Kunci: Chest Pass, Ketepatan, Sistem Pos}

\section{Pendahuluan}

Dalam perkembanganya, olahraga telah menjadi kebutuhan masyarakat untuk menjaga serta meningkakan kondisi fisik agar tetap semangat dalam melaksanakan aktivitas serta memiliki kemampuan untuk berprestasi. Hal ini sesuai dengan tujuan khusus dari aktivitas berolahraga yang dinyatakan muchtar dalam febri (2008), yaitu "kegiatan olahraga di Indonesia tidak hanya sekedar untuk keegaran jasmani saja atau rekreasi namaun harus berpikir kearah meningkatkan prestasi untuk dapat meningkatkan nama bangsa di gelanggang internasional".

Dalam UU RI No.3 tahun 2005 tentang sistem keolahragaan nasional "Keolahragaan nasional bertujuan memelihara dan meningkatkan kesehatan dan kebugaran, prestasi, kualitas manusia, menanamkan nilai moral dan ahlak yang mulia, sportifitas, disiplin, mempererat dan membina persatuan dan kesatuan

PJKR_

http://jurnal.unimed.ac.id/2012/index.php/jpehr/index 
bangsa, memperkukuh ketahanan nasional, serta mengangkat harkat, martabat dan kehormatan bangsa"

Rendahnya prestasi olahraga yang dicapai oleh masyarakat Indonesia khususnya cabang olahraga bola basket merupakan salah satu akibat dari kurang dan rendahnya kemampuan fisik, tehnik, taktik dan juga berdampak pada mental para pemain.

Permainan bola basket merupakan suatu bentuk olahraga permainan beregu yang berbentuk dinamis. Olahraga ini berasal dari Amerika Serikat, yang diciptakan oleh James A. Naismith. dia adalah seorang guru pendidikan jasmani Young Men's Christian Association (YMCA) di springfield, Massachusetts, Amerika Serikat pada tahun 1891. Permainan bola basket dimainkan oleh dua regu yang berlawanan. Tiap-tiap regu yang bermain terdiri dari lima orang pemain.

Bola basket sudah dikenal dengan baik di tengah-tengah masyarakat baik diseluruh negri maupun Indonesia, khususnya masyarakat di usia remaja. Olahraga bola basket dikenal melalui sekolah yaitu pada tingkat SMP dan SMA dimana usia mereka merupakan usia untuk olahraga prestasi. Olahraga bola basket harus memiliki kemampuan dan teknik yang sempurna. Ahmadi, (2007) mengemukakan bahwa untuk mencapai prestasi yang tinggi seorang pemain bola basket harus mempunyai tiga aspek yaitu (1) penguasaan teknik dasar (2) ketahanan fisik dan (3) kerjasama/pola dan strategi.

Menurut kosasih (2007) mengemukakan bahwa teknik dasar dalam bola basket adalah sebagai berikut: (1) teknik passing, (2) teknik dribbling, (3) teknik shooting, (4) teknik pivot, (5) teknik lay up shoot, dan (6) teknik rabound.

Teknik dasar mengoper (passing) adalah teknik dasar yang paling utama dalam permainan bola basket, karna adanya suatu operan dalam suatu tim dapat mengendalikan ritme pertandingan dan dapat membuka peluang untuk menjalankan strategi dan menciptakan skor. Ada banyak jenis operan dalam permainan bola basket yaitu: passing chest pass (operan setinggi dada), over hend (operan diatas kepala), dan bouncpass (operan dengan cara dipantulkan), Ahmadi Nuril (2007). Dalam permainan bola basket pasing merupakan faktor yang tidak kalah pentingnya dibandingkan dengan teknik-teknik lainnya yang harus dikuasai oleh seorang pemain bola basket salah satunya chest pass, karena dalam situasi tertentu kemahiran passing khususnya chest pass diperlukan untuk dapat melakukan umpan Fast break (serangan balik secara tiba-tiba) untuk menambah angka, tanpa menguasai teknik dasar chest pass suatu tim tidak akan berjalan dengan baik dalam suatu pertandingan.

Perlu diketahui tanpa latihan yang baik dan berulang-ulang atlet tidak akan dapat melakukan chest pass dengan benar dan tepat. Latihan yang berulang-ulang dengan model latihan yang bervariasi agar atlet tidak cepat merasa bosan. melalui latihan yang berulang-ulang dan menggunakan metode latihan yang bervariasi dilakukan, yang dikit demi sedikit ditambah intensitas dan kompleksitasnya maka atlet lama kelamaan akan berubah menjadi orang yang lebih lincah, lebih kuat, lebih terampil dan dengan sendirinya lebih efektif Harsono (1988) 
Chest pass bisa jadi tidak efektif apabila dalam pelaksanaannya tidak dilakukan dengan baik. Seperti saat melakukan chest pass bola dapat di rampas jika tidak dilakukan dengan hati-hati sehingga bola dikuasaai pihak lawan. Maka dari itu diperlukan latihan yang intensif untuk dapat melakukan chest pass dengan baik yaitu dengan melatih kemampuan passing, akurasi ketepatan dan kekuatan otot tangan dalam melakukan operan.

Dari hasil observasi yang penulis amati dilapangan pada saat sparing di lapangan basket SMA Negeri 2 Batang Hari, dari permainan tim bola basket putri SMA Negri 2 Batang Hari banyak melakukan kesalahan passing terutama chest pass sehingga bola dengan mudah dicuri lawan. Hal ini dapat dilihat dari banyaknya kesempatan tim putri SMA Negri 2 Batang Hari untuk mencetak angka namun pada saat akan mengoper kepada pemain satu timnya selalu dapat di rebut lawan akibat dari kesalahan cara passing dari pemain. Untuk mengatasi masalah ini perlu dilakukan latihan yang dapat meningkatkan kemampuan passing chest pass, salah satu latihan yang di anggap bisa mengatasi masalah ini adalah menggunakan metode latihan passing sistem pos, karna sistim ini lebih banyak memiliki berbagai macam bentuk latihan di dalamnya dan dengan menggunakan bentuk latihan ini akan mempermudah pelatih memberikan latihan-latihan passing chest pass kepada pemain agar lebih mudah dan cepat untuk menangkap apa yang di ajarkan pelatih sehingga mendapatkan hasil yang maksimal seperti yang di katakana, Harsono (1988), sistim pos adalah sistem latihan dengan melakukan sebanyak mungkin pekerjaan dan suatu jangka waktu tertentu atau melakukan suatu jumlah pekerjaan atau latihan dalam waktu yang sesingkat-singkatnya.

Permainan bola basket dimainkan oleh dua regu yang masing-masing regu berusaha memasukan bola ke dalam dalam keranjang lawan, mencegah lawan untuk memasukkan bola atau mencetak angka/skor dengan cara bola di oper, digelindingkan atau dribble sesuai dengan peraturan yang telah ditentukan, Kosasih (2007).

Menurut joni indarto (2014) permainan bola basket adalah olahraga bola berkelompok yang terdiri atas 2 tim beranggotakan masing-masing 5 orang yang saling bertanding mencetak point dengan memasukan bola ke dalam kerangjang lawan.

Menurut pendapat Rohim (2008) bahwa para pemain dibagi menjadi tiga kategori yaitu pemain tengah (centre), pemain depan (forward), dan pemain belakang (guardi). Dasar permainan bola basket yang harus diketahui oleh seorang pemain adalah: passing, dribbling, shooting, rebound, lay up shoot dan pivot. Dari teknik dasar dalm permainan bola basket, teknik mengoper (passing)adalah suatu keahlian yang sangat penting dan paling utama dalam Olahraga basket disamping teknik dasar yang lain seperti dribbling dan shooting.

Berdasarkan teori dan penelitian yang relevan diatas dapat di tarik kesimpulan bahwa permainan bola basket adalah suatu bentuk permainan yang dimainkan oleh 2 tim atau regu yang masing masing regu beranggotakan 5 orang, dimana setiap pemain ditugaskan mencegah lawan untuk memasukkan bola atau mencetak point dengan memasukan bola ke dalam kerangjang lawan.

PJKR_

http://jurnal.unimed.ac.id/2012/index.php/jpehr/index 
Adapun lembaga yang berwenang adalah persatuan Bola basket seluruh Indonesia (PERBASI) untuk sekala nasional, sedangkan untuk sekala internasional Federation Internationas Basketball de Amatuer (FIBA). Adapun teknik dasar permainan bola basket meliputi, menggiring bola (dribbling). Menggiring bola, dribbling adalah suatu cara untuk membawa bola ke segala arah lebih satu langkah dengan bola sambil dipantulkan dan merupakan suatu usaha untuk mengamankan bola dari rampasan lawan. Menurut pendapat Rohim, (2008: 18) ada beberapa jenis menggiring bola yakni:

1. Menggiring bola rendah

2. Menggiring bola tinggi

3. Menggiring bola campuran menurut kebutuhan.

Macam-macam dribble, yaitu:

1. Change of pace dribbling. Dribbling ini merupakan yang paling umum dalam bola basket dan digunakan untuk membuat pemain bertahan berfikir bahwa pelaku dribble akan memperlambat atau mempercepat tempo dribble.

2. Low or control dribble. Dribble ini adalah yang paling umum dalam bola basket dan digunakan untuk membuat pemain bertahan berfikir bahwa pelaku dribble akan mempercepat atau memperlambat dribble.

3. High or speed dribble. Ketika pemain berada dilapangan terbuka dan harus bergerak secepatnya dengan bola, maka dia akan menggunakan dribbling ini.

4. Crossover dribbling, yaitu mendribble bola dengan memindahkan bola dari tangan satu kearah tangan yang lain. Gerakan ini sangat baik untuk memperdaya lawan.

5. Behind the back dribble, jenis dribble ini digunakan ketika pemain mengganti arah supaya terbebas dari pemain lawan. Bola digerakan dari sisi tubuh yang satu ke sisi tubuh yang lain.

6. Between the legs dribble. Dribble ini adalah cara yang tepat untuk memindahkan bola dari satu tangan ketangan yang lain melewati sela kaki. Digunakan saat mendribble dijaga dengan ketat atau ingin mengganti arah.

7. Reverse dribble. Dribble ini digunakan untuk memindahkan bola dari satu tangan ketangan yang lain ketika dijaga dengan ketat. Dribble ini harus dilakukan dengan cepat saat pendribble mendorong bola kelantai dan berputar mengelilingi pemain bertahan lawan.

Sistem pos atau latihan sirkuit diperkenalkan oleh morgan dan adamson pada 1953 di University of Leeds di Inggris. Menurut Nossek yang di kutip oleh Bambang Priyonoadi (1982) latihan ini adalah proses untuk mengembangkan penampilan olahraga yang kompleks dengan memakai isi latihan, metode latihan, tindakan organisasional dengan tujuan.

Menurut Sujoto (1995) brntuk latihan ini merupakan suatu program latihan yang terdiri dari stasiun-stasiun dan di setiap stasiun ini seorang harus melakukan jenis latiha yang telah di tentukan. Menurut Kosasih (2008) sistim pos merupakan suatu cara mengajar dengan latihan latihan terhadap apa yang telah di pelajari 
sehingga memperoleh keterampilan tertentu selain memberikan latihan ada yang berpendapat bahwa model latihan ini merupakan latihan yang di lakukan berulang-ulang. Dari pendapat para ahli di atas dapat di simpulkan bahwa model latihan melalui sistem pos harus dilakukan secara teratur dan terus menerus sesuai dengan program latihan yang telah di tentukan.

Model Latihan Sistem Pos, menurut Sukadianto (2005) latihan sistem pos adalah ukuran keberhasialan dalam menyelesaikan beberapa rangkaian butira latihan yang berbeda beda. Bompa (1994) juga mengemukakan bahwa sistem pos merupakan metode latihan dengan mengorganisasikan pos pos dalam suatu rangkaian lingkaran latihan, artinya dalam suatu sirkuit terdiri atas beberapa macam latihan yang semua harus di selesaikan dalam satu rangkaian.Sirkuit latihan dinyatakan selesai apabila seseorang telah menyelesaikan disemua stasiun sesuai atauran dan waktu yang telah di tetapkan dan singkat nya adalah satu bentuk latihan yang di lakukan dalam satu putaran, selama satu putaran tersebut terdapat beberapa point.

Di setiap latihan dilaksanakan untuk nomor yang spesifik pada setiap repetisi dan di selesaikan salama waktu tertentu dbelum pindah pada latihan berikutnya dalam latihan sistem ini di pisahkan oleh petunjuk, waktu istirahat (interval) dan setiap sirkuit di pisahkan oleh waktu istirahat yang panjang jumlah pos pada sirkuit yang dilaksanakan selama satu kali sesi latihan mungkin berubah ubah mulai dari 2-6 pos, 8, 10 pos dan 12 pos tergantung pada level latihan

Latihan ini merupakan kombinasi dari semua unsur fisik. Jenis latihanya dari lari naik turun tangga, lari ke samping, ke belakang, lempar bola, memukul bola, melompat, berbagai bentuk latihan beban, setiap pos lari zigzag, full up, dan sebagainya.

a) Prinsip latihan dengan sistem pos sebagai berikut

1. Melakukan sebanyak mugkin pekerjaan dalam jangka waktu tertentu

2. Lakukan suatu jumlah pekerjaan atau latihan dalam waktu yang sesingkat-singkatnya

b) Cara melakukan model latihan sistem pos. Cara melakukannya sebagai berikut:

1. Dalam satu daerah atau area tertentu di tentukan beberapa pos atau stasiun, misalnya 5-10 pos

2. Disetiap pos atlit di haruskan melakukan suatu bentuk latihan tertentu

3. Latihan-latihan yang dilakukan biasanya berbentuk latihan -latihan kondisi fisik seperti kekuatan, kecepatan, kelincahan, dan daya tahan sebagainya

4. Latihan dapat dilakukan tanpa atau dengan menggunakan bobot atau beban

5. Bentuk-bentuk latihan pada setiap pos adalah lari zigzag, full up, lempar bola, medicine, squat jumps, naik turun tangga, prees, aquat thrust, rowing, dan lari 400m secepatnya

Dalam melakukan setiap bentuk latihan sirkuit, guru dapat menentukan variasi-variasi sebagai berikut:

PJKR_

http://jurnal.unimed.ac.id/2012/index.php/jpehr/index 
1. Harus dilakukan pengulangan

2. Harus melakukan sebanyak mungkin pengulangan dalam waktu tertentu misalnya 15 detik

3. Demikian pula dapat ditetapkan apakah setelah tiap bentuk latihan ada masa istirahatnya misalnya 15 detik atau tidak

Bentuk-bentuk Latihan Passing Sistem Pos, dalam penelitian ini penulis memberikan model latihan passing melalui sistem pos, latihan ini dilakukan agar dapat hasil yang optimal dengan caramelakukan sebanyak mungkin latihan dalam jangka waktu tertentu dan melakukan bentuk latihan dengan benar dan dalam norma-norma yang dilakukan. Dibawah ini adalah bentuk-bentuk latihan sistem pos yang digunakan dalam penelitian ini:

\section{Pos 1 Passing Chest Pass Bergantian Dengan Saling Berhadapan}

Passing Chest Pass Bergantian dengan saling berhadapan merupakan salah satu bentuk latihan passing dalam permainan bola basket Latihan ini berguna untuk menambah kemampuan dan ketepatan passing pemain. Cara melakukan bentuk latihan Chest Pass Bergantian Dengan saling berhadapan yaitu Pemain saling menghadap dengan 1 bola. Kemudian melakukan chest pass ke teman didepannya. Setelah melakukan chest pass pemain berlari kebelakang pemain penerima bola.

\section{Pos 2 Chest Pass Bentuk Segi Tiga}

Passing Chest Pass Bentuk Segi Tiga merupakann salah satu bentuk latihan passing pada permainan bola basket maanfaat atau kegunaan latihan chest pass bentuk segi tiga ini untuk melatih operan dan tangkapan pemain saat menerima operan. Cara melakukan bentuk latihan Chest Pass Bentuk Segi Tiga ini yaitudengan membentuk Tiga regu lalu masing masing regu diatur sesuai diagram. Bola dioperkan kepemain disebelahnya dengan operan chest pass. Dan dari sana diperoleh kembali bola keregu pertama. Pemain yang telah melakukan operan langsung berlari kebelakang dalam barisannya.

\section{Pos 3Chest Pass Bergantian Sambil Berlari Kedepan}

Passing Chest Pass Bergantian Sambil Berlari Kedepan merupakan salah satu bentuk latihan passing pada permainan bola basket maanfaat atau kegunaan latihan ini adalah untuk menambah kemampuan passing pemain pada saat menyerang karena gerakan passing ini dilakukan sambil berlari ke depan. Cara melakukan bentuk latihan Chest PassBergantian Sambil Berlari Kedepan yaitu dengan caraDua orang pemain melakukan chest pass bergantian sambil berlari ke depan untuk menerima operan bola kembali. Operan dilakukan sesuai dengan perintah pelatih.

PJKR_

http://jurnal.unimed.ac.id/2012/index.php/jpehr/index 


\section{Pos 4 Chest Pass Bentuk Zig-Zag}

Passing Chest PassBentuk Zig-Zag merupakan salah satu bentuk latihan passing pada permainan bola basket maanfaat atau kegunaan latihan ini adalah untuk menambah kecepatan passing dan ketepatan passing. Cara melakukan bentuk latihan Chest Pass Bentuk Zig-Zag yaitu dengan cara beberapa orang pemain dibagi menjadi dua barisan. Pemain pertama di salah satu barisan melakukan chest passdengan cepat ke barisan sebelahnya kemudian penerima operan mengoper ke barisan sbelumnya dengen membentuk operan zig-zag.

5. Pos 5 Latihan Chest Pass Ke Dinding/Tembok

Passing Chest Pass Ke Dinding/Tembok merupakan salah satu bentuk latihan passing pada permainan bola basket maanfaat atau kegunaan latihan ini adalah untuk meningkatkan akurasi/ketepatan dan kemampuan operan chest pass. Cara melakukan bentuk latihan Chest Pass Ke Dinding/Tembok yaitu beberapa orang pemain berbaris kearah dinding/tembok. Pemain dibarisan paling depan melakukan chest pass ke dinding/tembok. Setelah melakukan chest pass pemain tersebut bergerak ke barisan paling belakang. Pemain berikutnya melakukan gerakan yang sama sesuai perintah dari pelatih.

\section{Metode}

Penelitian ini meggunakan metode eksperimen dalam penelitian ini terdapat suatu kelompok eksperimen yang sengaja diberi perlakuan dengan menggunakan rencana One Group pretes-postest design. Pelaksanaan dan pengambilan data ini dilakukan di lapangan basket SMA Negeri 2 Batang Hari dan merupakan tempat latihan tim bola basket putri SMA Negeri 2 Batang Hari. Dalam penelitian ini peneliti berencana melakukan treatment (perlakuan) selama 6 minggu dengan jadwal latihan 3 kali seminggu. Adapun populasi dari penelitian ini adalah tim bola basket putri SMA Negeri 2 Batang Hari, yang terdiri dari 15 orang. Sehingga seluruh populasi diangkat menjadi sampel yaitu tim bola basket putri SMA Negeri 2 Batang Hari sebanyak 15 orang.

Untuk memperoleh data dalam penelitian ini dilakukan tes kemampuan (tes performance) dengan cara chest pass tes pada pre test dan post test. Dalam analisis data penelitian awal dan akhir guna melihat hasil penelitian chest pass pada sampel eksperimen, kemudian dilakukan analisis uji kesamaan dua rata-rata dengan uji-t, sebelumnya dilakukan uji normalitas dan uji homogenitas, sudjana (2005). Apabila kedua sampel normal dan homogen rumus yang digunakan untuk pengujian hipotesis adalah uji-t.

\section{Pembahasan}

Berdasarkan dari data yang telah dikumpulkan sebelumnya, maka di dalam bab ini akan dilakukan analisis pembahasan yang di peroleh dalam penelitian ini. 
Hasil penelitian ini digambarkan sesuai dengan tujuan dan hipotesis yang diajukan sebelumnya. Gambaran dari data hasil penelitian dapat dilihat pada deskripsi berikut ini:

Tes awal Ketepatan Passing Chest Pass

Tes awal pada penelitian ini belum diberikan latihan sistem pos, pada tes awal ini di dapatkan ketepatan passing chest pass tim bola basket putri SMA Negeri 2 Batang Hari dengan jumlah keseluruhan 161, dengan demikian hasil rata - rata ketepatan passing chest pass tim bola basket putri SMA Negeri 2 Batang Hari sebesar 10,73.

\begin{tabular}{|c|c|c|}
\hline NAMA & TES AWAL & KETERANGAN \\
\hline Yuli Ayundari & 5 & Kurang Sekali \\
\hline Ani Zuhriatul Janna & 9 & Kurang Sekali \\
\hline Endah Ayunda & 12 & Kurang \\
\hline Bella Permata Sari & 14 & Kurang \\
\hline Irma Saputri & 13 & Kurang \\
\hline Nur Azizah & 8 & Kurang Sekali \\
\hline Fitri Aisha & 15 & Cukup \\
\hline Ayu Oktaviana & 11 & Kurang \\
\hline Ditta Fajriani & 9 & Kurang Sekali \\
\hline Wiwik Harjanti & 10 & Kurang \\
\hline Rizka Alvionita & 16 & Cukup \\
\hline Niken Wulandari & 7 & Kurang Sekali \\
\hline Siti Harjanti & 17 & Cukup \\
\hline Miftahur Rohifa & 9 & Kurang Sekali \\
\hline Khusnul Khotimah & 6 & Kurang Sekali \\
\hline JUMLAH & 161 & \\
\hline MEAN & 10,73 & \\
\hline SKOR MAX & 17 & \\
\hline SKOR MIN & 5 & \\
\hline SD & 3,67 & \\
\hline VARIAN & 13,50 & \\
\hline
\end{tabular}

\section{Tes Akhir Ketepatan Passing Chest Pass}

Tes akhir pada penelitian ini merupakan tes yang dilakukan setelah adanya perlakuan pada sampel yang diteliti, sehingga pada tes akhir ini merupakan tes setelah melakukan latihan sistem pos secara intensif selama 6 minggu. Pada tes akhir ini di dapatkan Ketepatan Passing Chest Pass Tim Bola Basket Putri SMA 
N 2 Batang Hari dengan jumlah keseluruhan 187, dengan demikian Ketepatan Passing Chest Pass Tim Bola Basket Putri SMA N 2 Batang Hari sebesar 12,47.

Jika dilihat dari rata-rata Ketepatan Passing Chest Pass Tim Bola Basket Putri SMA N 2 Batang Hari pada tes awal sebesar 10,73 dibandingkan dengan Ketepatan Passing Chest Pass Tim Bola Basket Putri SMA N 2 Batang Hari pada tes akhir sebesar 12,47, tampak terlihat perbedaan diantara ke dua hasil tersebut sebesar 1,74, dengan kata lain terdapat peningkatan ketepatan.

Tabel 2. Tes Akhir Ketepatan Passing Chest Pass

\begin{tabular}{|c|c|c|}
\hline NAMA & TES AKHIR & KETERANGAN \\
\hline Yuli Ayundari & 7 & Kurang Sekali \\
\hline Ani Zuhriatul Janna & 10 & Kurang \\
\hline Endah Ayunda & 14 & Kurang \\
\hline Bella Permata Sari & 15 & Cukup \\
\hline Irma Saputri & 14 & Kurang \\
\hline Nur Azizah & 11 & Kurang \\
\hline Fitri Aisha & 17 & Cukup \\
\hline Ayu Oktaviana & 13 & Kurang \\
\hline Ditta Fajriani & 10 & Kurang \\
\hline Wiwik Harjanti & 12 & Kurang \\
\hline Rizka Alvionita & 18 & Cukup \\
\hline Niken Wulandari & 8 & Kurang Sekali \\
\hline Siti Harjanti & 19 & Cukup \\
\hline Miftahur Rohifa & 12 & Kurang \\
\hline Khusnul Khotimah & 7 & Kurang Sekali \\
\hline JUMLAH & 187 & \\
\hline MEAN & 12,47 & \\
\hline SKOR MAX & 19 & \\
\hline SKOR MIN & 7 & \\
\hline SD & 3.77 & \\
\hline VARIAN & 14,26 & \\
\hline
\end{tabular}

Pada rancangan penelitian telah dikemukakan bahwa untuk melihat pengaruh latihan sistem pos maka digunakan analisis perbedaan. Adapun persyaratan analisis perbedaan adalah:

\section{Uji Normalitas}

Berikut ini adalah tabel hasil penelitian latihan sistem pos terhadap Ketepatan Passing Chest Pass Tim Bola Basket Putri SMA N 2 Batang Hari sebagai berikut: 
Tabel 3. Hasil Uji Normalitas Tes Ketepatan Passing Chest Pass

\begin{tabular}{rccrrc}
\hline No & Kelas & N & LHitung & \multicolumn{1}{c}{ LTabel } & Keterangan \\
\hline $\mathbf{1}$ & Data Test Awal & 15 & 0,01306 & 0,220 & Normal \\
\hline $\mathbf{2}$ & Data Test Akhir & 15 & 0,00724 & 0,220 & Normal \\
\hline
\end{tabular}

Uji normalitas ini bertujuan untuk mengetahui apakah data penelitian yang diperoleh berdistribusi normal atau tidak. Uji normalitas yang digunakan adalah uji liliefors dengan kriteria data berdistribusi normal apabila LHitung < LTabel. Terdapat hasil data pada tes awal sebesar 0,013061 maka dapat dinyatakan nilai LHitung $=0,013061$ dan setelah dilihat nilai pembanding pada tabel L dinyatakan nilai LTabel $=0,220$ ditarik kesimpulan LHitung $=0,013061<$ LTabel $=0,220$ maka dinyatakan normal, dan hasil data pada tes akhir sebesar 0,00724 maka dapat dinyatakan nilai LHitung $=0,00724$ dan setelah dilihat nilai pembanding pada tabel L dapat dinyatakan nilai LTabel $=0,220$ hasil data tesakhir LHitung $=$ $0,00724<$ LTabel $=0,220$ maka dikatakan normal.

\section{Uji Homogenitas Varians}

Untuk menentukan apakah varian sampel homogen atau tidak, maka diajukan uji homogenitas yang menggunakan rumus:

$$
F=\frac{s_{1}^{2}}{s_{2}^{2}}=\frac{13,50}{14,26}=0,95
$$

Tabel 4. Hasil Uji Homogenitas Tes Ketepatan Passing Chest Pass

\begin{tabular}{|c|c|c|c|c|c|c|}
\hline No & Kelas & $\mathbf{N}$ & $\mathbf{S}$ & $\begin{array}{c}\text { FHitun } \\
\text { g }\end{array}$ & FTabel & Keterangan \\
\hline 1 & Data tes awal & 15 & 13,50 & 0,95 & 2,48 & Homogen \\
\hline 2 & Data tes akhir & 15 & 14,26 & & & \\
\hline
\end{tabular}

Uji ini bertujuan untuk melihat apakah data pree-test dan post-test mempunyai varians yang homogen atau tidak. Uji homogenitas varians ini menggunakan rumus uji F, dikatakan homogen apabila FHitung < FTabel. Hasil nilai $S^{1}$ pada tes awal 13,50 dibagi hasil nilai $S^{2}$ pada tes akhir 14,26 maka mendapatkan nilai FHitung $=0,95$. Dan nilai perbandingan pada FTabel $=2,48$, maka hasil data tes awal dan akhir FHitung 0,95 < Ftabel 2,48 maka dikatakan homogen.

\section{Uji Hipotesis (Uji T)}

Tabel 5. Hasil Uji Hipotesis Tes Ketepatan Passing Chest Pass

\begin{tabular}{cccccccc}
\hline No & $\mathbf{N}$ & $\boldsymbol{\Sigma} \boldsymbol{x}^{\mathbf{2}} \mathbf{d}$ & Thitung & Ttabel & \multicolumn{2}{c}{ Keterangan } \\
\hline $\mathbf{1}$ & 15 & 6,94 & 7,61 & 1,7613 & $\begin{array}{l}\text { Di terima pada } \\
\text { kepercayaan 95\% }\end{array}$ & tingkat \\
& & & & &
\end{tabular}




$$
\begin{aligned}
& \mathrm{t}=\frac{M d}{\sqrt{\frac{\sum X^{2} d}{N(N-1)}}} \\
& \mathrm{t}=\frac{1,37}{\sqrt{\frac{6,94}{15(15-1)}}} \\
& \mathrm{t}=\frac{1,37}{0,18} \\
& \mathrm{t}=7,61
\end{aligned}
$$

Dari hasil perhitungan dapat diketahui dengan jumlah 15 sampel dan thitung 7,61 untuk melihat apakah hipotesis $\mathrm{H} 1$ atau $\mathrm{H} 0$ yang diterima sesuai penjelasan diatas maka dibandingkan harga thitung dengan ttabel. Perbandingan harga antara thitung dengan ttabel dengan nilai dari table distribusi t untuk taraf nyata $\alpha=0,05$ dengan derajat kebebasan $=(n-1)=(15-1)=14$, diperoleh thitung $(7,61)>$ ttabel $(1,7613)$. Maka hasil data hipotesis thitung 7,61 > ttabel 1,7613 maka diterima pada tingkat kepercayaan 95\%. Kesimpulannya adalah terdapat pengaruh latihan beban di kaki dan lari di tanjakan terhadap Ketepatan Passing Chest Pass Tim Bola Basket Putri SMA N 2 Batang Hari.

Berdasarkan pengujian yang telah dilakukan peneliti terlihat bahwa sistem pos berpengaruh terhadap upaya meningkatkan ketepatan passing chest pass pada tim bola basket putri SMA negeri 2 batang hari dikarnakan metode latihan dengan sistem pos ini memiliki banyak bentuk latihan di dalamnya, latihan-latihan yang di gunakan dalam penelitian ini adalah latihan passing chest pass saling berhadapan, passing chest pass bentuk segi tiga, pasing chest pass bergantian sambil berlari kedepan, passing chest pass bentuk zig-zag, pasing chest pass kedinding/tembok yang mampu meningkatkan kemampuan ketepatan chest pass pada tim bola basket SMA negeri 2 batang hari.

Selain itu latihan dengan sistem pos ini tidak membutuhkan waktu yang lama, hal tersebut sangat pas dengan waktu dua bulan penelitian yang dimulai dari 31 maret s/d 31 mei 2016 yang diberikan. Dilihat dari hasil penelitian yang telah dilakukan oleh peneliti selama dua bulan tampak bahwa latihan-latihan yang diberikan mampu meningkatkan ketepatan chest pass terhadap tim bola basket putri SMA negeri 2 batang hari.

\section{Simpulan}

Berdasarkan Pembahasan data diatas bahwa dapat disimpulkan "terdapat pengaruh latihan Sistem Pos terhadap ketepatan Passing Chest Pass Tim Bola Basket Putri SMA N 2 Batang Hari”.

PJKR_

http://jurnal.unimed.ac.id/2012/index.php/jpehr/index 


\section{Rujukan}

Ahmadi, Nuril, 2007. Permainan Bola Basket. Solo: Era Intermedia

Arikunto, Suharsini, 2010. Prosedur Penelitian Suatu Pendekatan Praktik. Jakarta: PT. Rineka Cipta

Aryanto, Saddam, 2009. Pengaruh Latihan Variasi Drill Passing dan Wall Passing Terhadap Kemampuan Chest Pass Pada Pemain Bola Basket SMA Negeri 7 Kota Jambi.

Depdikbud, 1977. Bola Basket. Jakarta: Depdikbud

Endarman, 2010. Physical conditioning metode melatih kondisi fisik. Jambi

Harsono, 1988. Coaching dan aspek-aspek psikologis dalam coaching. Jakarta:

CV. Tambak Kusuma

Ilham, 2011. Hubungan Kekuatan Otot Lengan Dengan Kemampuan Chest Pass

Pemain Bola Basket Siswa SMP negeri 11 Kota Jambi. Jurnal.Volume

13. Nomor 1. Hal. 13-18. Januari- juni 2011. Jambi: Universitas Jambi

Kosasih, Danny, 2007. Fundamental Basket Ball. Semarang: Karmedia

Monayo, Yulianti, 2014. Meningkatkan Kemampuan Chest Pass Melalui Model Pembelajaran Kooperatif Tipe Group Investigasi Pada Siswa Kelas VII SMP Negeri 6 Gorontalo Kota Gorontalo

Muchtar, Febri. 2008. Olahraga Pilihan Sepak Bola. Depdikbud Dirjen Pendidikan Tinggi Proyek Pembinaan Tenaga Pendidik: Jakarta

Oliver, Jon, 2003. Dasar-Dasar Bola Basket. Bandung: Pakar Raya

Rohima, 2015. Pengaruh Latihan Mengoper Bola Ketembok dan Berpasangan Terhadap Keterampilan Chest Pass.

Rohim, Abdul, 2008. Olahraga Bola Basket. Semarang: Aneka Ilmu

Salim, agus, 2008. Buku pintar bola basket. Bandung: Nuansa

Suparno dan suwadi, 2008. Penjasporkes. Jakarta: Bumi aksara

Sajoto, M, 1988. peningkatan dan pembinaan kondisi fisik dalam olahraga. Dahara prize.

Sigit Nogroho, 2013. (Pengaruh latihan sirkuit (sircuit traning) terhadap daya tahan erobik (vo2 max) mahasiswa pko fakultas ilmu keolahragaan universitas negri Yogyakarta. Yogyakarta: Universitas Negeri Yogyakarta

Solihin, Muhammad, 2012. Pengaruh Variasi Drill Passing Tehadap Accuracy Chest PassTim Bola Basket Siswa Putra SMA Negeri 9 Kota Jambi. Jambi: Universitas Jambi

Sugiyono, 2008. Metode penelitian kuantitatip, kualitatif dan R\&D. Bandung: CV Alfa Beta.

Sudjana, 2005. Metode Statistika. Bandung: Tarsito

Undang-undang republik Indonesia nomor. 3 tahun 2005 tentang system keolahragaan nasional.

Wissel, Hal, 2007. Bola Basket. Jakarta: Rajawali Sport 